\title{
Relation of out of hours activity by general practice and accident and emergency services with deprivation in Nottingham: longitudinal survey
}

\author{
Robin Carlisle, Lindsay M Groom, Anthony J Avery, Daphne Boot, Stephen Earwicker
}

\section{See $p 524$}

Division of General Practice, University of Nottingham,

University Hospital, Nottingham

NG7 2UH

Robin Carlisle,

lecturer

Lindsay M Groom,

research unit

coordinator

Anthony J Avery,

senior lecturer

Daphne Boot,

research associate

Stapleford Health

Centre, Nottingham

NG9 7AT

Stephen Earwicker,

general practitioner

Correspondence to:

Dr R Carlisle,

Roundwood

Surgery, Wood

Street, Mansfield,

Nottinghamshire

NG18 1QQ

BMJ 1998;316:520-3

\begin{abstract}
Objectives: To investigate the relation between out of hours activity of general practice and accident and emergency services with deprivation and distance from accident and emergency department.

Design: Six month longitudinal study.

Setting: Six general practices and the sole accident and emergency department in Nottingham.

Subjects: 4745 out of hours contacts generated by 45182 patients from 23 electoral wards registered with six practices.
\end{abstract}

Main outcome measures: Rates of out of hours contacts for general practice and accident and emergency services calculated by electoral ward; Jarman and Townsend deprivation scores and distance from accident and emergency department of electoral wards.

Results: Distances of wards from accident and emergency department ranged from 0.8 to $9 \mathrm{~km}$, and Jarman deprivation scores ranged from -23.4 to 51.8 . Out of hours contacts varied by ward from 110 to 350 events/1000 patients/year, and $58 \%$ of this variation was explained by the Jarman score. General practice and accident and emergency rates were positively correlated (Pearson coefficient 0.50, $\mathrm{P}=0.015$ ).

Proximity to accident and emergency department was not significantly associated with increased activity when deprivation was included in regression analysis. One practice had substantially higher out of hours activity (B coefficient 124 (95\% confidence interval 67 to 181)) even when deprivation was included in regression analysis.

Conclusions: A disproportionate amount of out of hours workload fell on deprived inner city practices. High general practice and high accident and emergency activity occurred in the same areas rather than one service substituting for the other.

\section{Introduction}

The extent to which deprivation influences the demand for out of hours medical care is not fully explained. ${ }^{1}$ Studies of single general practices have shown high workload in deprived areas, ${ }^{2}$ but other studies of practices in affluent areas have also found high workloads. ${ }^{4}$ Studies of multiple practices have been able to explain only a small percentage of the variation in claims for night visits by socioeconomic factors. ${ }^{5}{ }^{6}$

It has been hard to quantify the effect of deprivation on use of accident and emergency departments because they do not serve defined populations. ${ }^{7-9}$ It has been suggested that there is less out of hours activity in general practices in inner cities than would otherwise be expected because of the proximity of accident and emergency departments. ${ }^{10}{ }^{11}$ At a time of increasing pressure on both services, it is important to understand the factors that influence demand for out of hours care.

\section{Methods}

We recruited six practices with 34 general practitioners which covered an area from inner city Nottingham, close to the sole accident and emergency department, through to suburban areas west of the city centre. Three suburban practices provided their own out of hours cover, while one suburban practice and two inner city practices used a deputising service for some of their calls. Four practices participated in undergraduate teaching. There were no differences between the practices in daytime policy for visiting or accommodating urgent cases. Out of hours was defined as $7 \mathrm{pm}$ to 759 am on weekdays and weekends from noon on Saturday.

Our aim was to collect information for all contacts with the general practices and accident and emergency department during the first six months of 1996, and we calculated annual rates by doubling the six months' figures. We collected data on general practices with a specially designed form and collected information on the deputising service and the accident and emergency department from routine data. Rates of activity for general practices and the deputising service included visits and telephone advice, while rates for the accident and emergency service excluded patients referred by general practitioners and telephone advice.

We used patients' postcodes to determine the number of patients registered and the number of out of hours events for each electoral ward. As an indicator of proximity to the accident and emergency service, we calculated the linear distance from the grid reference of each ward's centroid, weighted for population, to the grid reference of the accident and emergency department. We assigned Jarman (UPA 8) ${ }^{12}$ and 
Townsend $^{13}$ deprivation scores and their component variables to the electoral wards using data from the 1991 census, and we calculated Jarman scores for each general practice from the ward scores and the number of patients in each ward registered with the practice.

\section{Statistical analysis}

We analysed the data using sPss for Windows version 6 . To reduce the effects of variations in rates for wards with small numbers and to be more sure that the census data were representative of the study population, we restricted the analysis to the 23 wards with more than 199 patients from the practices in the study. We performed linear regression with the weighted least squares option, using wards' levels of out of hours activity as dependent variables and deprivation scores, distances, or individual census components as separate independent variables. We checked assumptions with normal probability plots and analysis of residuals.

We performed multiple regression to investigate whether the effects of distance from the accident and emergency department and deprivation were independent. Inclusion criterion was a probability associated with the $F$ statistic of $\leqslant 0.05$. To establish whether practices had differing levels of out of hours activity when deprivation was controlled for, we calculated practice-specific out of hours rates for wards in which individual practices had more than 199 patients. These values were used as dependent variables and analysed by multiple regression forward stepwise entry, with Jarman score as a continuous variable and binary dummy variables comparing five practices against the largest practice used as a constant.

\section{Results}

\section{Data analysed}

Of the 46698 patients registered with the six general practices, 45182 (97\%) lived in the 23 wards studied. Of 5057 out of hours events recorded, 4742 (94\%) occurred in the 23 wards (2019 contacts with the general practitioners, 1016 with the deputising service, and 1707 with the accident and emergency department). We are preparing a separate paper on substantial differences in case mix between the services: most general practice contacts were for minor illness, while half of accident and emergency contacts were for accidents and injuries.

Distances between wards and the accident and emergency department ranged from $0.83 \mathrm{~km}$ to $9 \mathrm{~km}$. Jarman scores ranged from - 23.4 to 51.8 (national average $=0$ (SD 16), positive values representing relative deprivation). There was a negative correlation between distance and Jarman score (Pearson coefficient 0.59) because of higher deprivation in wards close to the accident and emergency department.

\section{Out of hours activity}

By individual practice-Table 1 shows the out of hours activity and Jarman score for each of the general practices. Five practices (B-F) had relatively similar rates of out of hours contacts of between 164 and 227 events/1000 patients/year, whereas the most deprived practice (A) had a rate nearly twice the average.

By ward-General practice contacts varied between wards from 64 to 229 events/1000 patients/year (SD
Table 1 Out of hours activity generated by different general practice populations and estimated Jarman deprivation score against out of hours activity rates

\begin{tabular}{lccccc} 
& & & \multicolumn{2}{c}{ No of out of hours events/1000 patients/year } \\
\cline { 4 - 6 } $\begin{array}{l}\text { General } \\
\text { practice }\end{array}$ & $\begin{array}{c}\text { Practice } \\
\text { population } \\
(\mathbf{n = 4 5} \mathbf{1 8 2})^{*}\end{array}$ & $\begin{array}{c}\text { Estimated Jarman } \\
\text { score† }\end{array}$ & $\begin{array}{c}\text { By general } \\
\text { practice }\end{array}$ & $\begin{array}{c}\text { By accident and } \\
\text { emergency } \\
\text { department }\end{array}$ & All \\
\hline A & 2603 & 36.2 & 271.5 & 136.5 & 408.1 \\
\hline B & 9321 & 17.7 & 134.6 & 92.7 & 227.3 \\
\hline $\mathrm{C}$ & 7951 & -1.6 & 153.2 & 57.2 & 210.4 \\
\hline $\mathrm{D}$ & 11084 & 1.8 & 126.1 & 74.2 & 200.3 \\
\hline E & 5414 & -2.7 & 113.4 & 79.6 & 193.0 \\
\hline F & 8809 & -5.3 & 105.8 & 58.5 & 164.4 \\
\hline Average & - & 4.5 & 134.4 & 75.6 & 209.9 \\
\hline
\end{tabular}

${ }^{*}$ Those resident in the 23 electoral wards included in study.

†Calculated from Jarman scores for each ward that patients came from.

42). Accident and emergency rates varied from 21 to 153 (SD 29). As was expected, wards with smaller registered populations showed more variability in rates, but there was no significant correlation between the size of the registered population and out of hours activity $(\mathrm{P}=0.81)$ : the 12 wards with more than 2000 patients had a mean combined rate of 210 events/1000 patients/year (SD 43, range 157-305), and the 11 wards with 200-2000 patients had a mean of 220 (SD 80, range 110-350). General practice rates and accident and emergency rates were positively correlated with each other by ward (Pearson coefficient $0.50, \mathrm{P}=0.015$ ).

By deprivation measures-Higher rates for both services were associated with higher deprivation scores. The Jarman score explained $46 \%$ of variation in general practice rates and $43 \%$ of variation in accident and emergency rates (figure). For combined rates, the Jarman score explained $58 \%$ of the variation, and the Townsend score explained $56 \%$. Six of the eight component variables of the Jarman score and all four components of the Townsend score were individually associated with combined rates of out of hours contacts (table 2). Areas with overcrowding, unemployment, more non-owner occupation, low car ownership, and increased ethnicity were all associated with higher rates for both services. Areas with more single parents were also associated with higher rates but with a higher coefficient for general practice contacts than for accident and emergency attendances $(95 \%$ confidence interval of B coefficient of 8.8 to 17.2 compared with 0.8 to 8.5 ). The proportion of children aged under 5 was positively related to general practice contacts but not accident and emergency rates, while having moved house within a year was significantly related only to accident and emergency rates. Two variables (unskilled and elderly living alone) had no significant association with out of hours activity.

By distance from accident and emergency departmentGreater proximity of wards to the accident and emergency department was associated with increased use of this service. However, when accident and emergency rates or combined rates were analysed by multiple regression with Jarman score and distance together, distance did not add significantly to Jarman score used alone.

Multivariate analysis of practice-specific out of hours rates -We limited the analysis to those wards from which at least 200 patients were registered with a single general practice: in 15 wards two practices met this criterion and in six wards one practice did so, giving 36 practice-specific out of hours rates. Between four and 


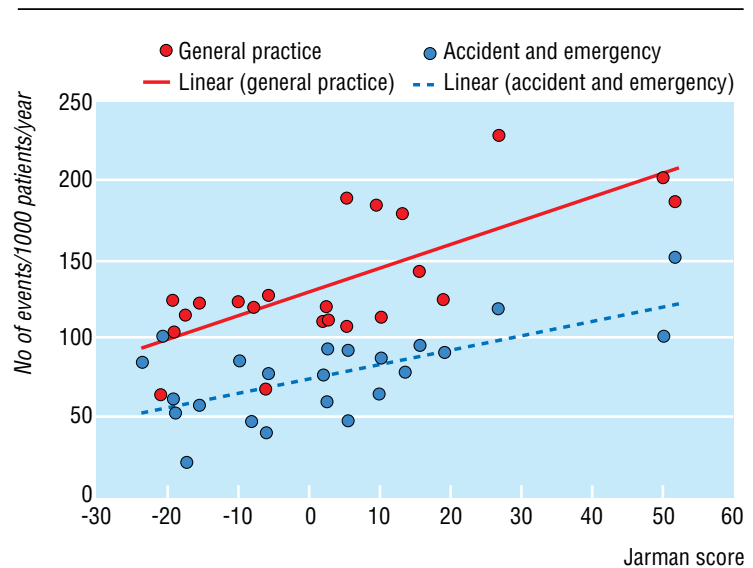

Out of hours activity of general practices and accident and emergency department against Jarman deprivation score for 23 electoral wards

eight wards per practice met the criterion. Multiple regression showed that higher total out of hours activity was independently associated with registration with one particular practice, A (B coefficient 124 (95\% confidence interval 67 to 181) $\mathrm{P}=0.0001)$ and with Jarman score (B coefficient 1.3 (0.4 to 2.1) $\mathrm{P}=0.007$ ): these two factors together explained $66 \%$ of the variation. None of the other practices differed significantly from the constant.

\section{Discussion}

Although there may have been some underrecording of general practice telephone contacts, we believe that the data give an acceptable picture of out of hours activity for the period described. The fact that the practices were willing to record detailed information suggests that they may have been less varied than average in terms of their practice organisation. Nevertheless, they covered an area with broad socioeconomic variability.

\section{Out of hours activity}

Out of hours activity for general practices and the accident and emergency department varied substantially between areas. For wards with smaller numbers, some of the variation would have been due to chance, ${ }^{14}$ but even when the analysis is restricted to the 12 wards containing more than 2000 patients activity varies nearly twofold.

Whether considered by individual general practice or by area, the general practice rates and accident and emergency activity were positively correlated. We found no evidence of accident and emergency activity substituting for general practice contacts. Our results suggest that if some accident and emergency work is diverted to general practice some practices will be affected more than others and those most affected would already have the highest workload.

Although distance from the accident and emergency department had a significant negative association with out of hours rates, the association disappeared when deprivation was taken into account. This result has to be interpreted with caution because the range of distances was small and distance and deprivation were correlated. However, it suggests that in Nottingham the high activity from areas close to the accident and emergency department was because of deprivation rather than proximity. This contradicts a study from Northern Ireland, ${ }^{15}$ where distance was more important than socioeconomic characteristics in explaining accident and emergency attendances over a larger area.

\section{Deprivation}

Deprivation score could explain 58\% of the variation in out of hours activity between wards. This is a high figure for a regression analysis of a general practice variable and suggests that out of hours activity is more strongly associated with deprivation than either daytime consultation rates ${ }^{16}$ or referral rates. ${ }^{17} \mathrm{~A}$ difference in Jarman

Table 2 Univariate linear regression of deprivation scores, distance from accident and emergency department, and census variables with out of hours activity of general practice and accident and emergency services

\begin{tabular}{|c|c|c|c|c|c|c|c|c|c|}
\hline \multirow[b]{2}{*}{ Independent variables* } & \multicolumn{3}{|c|}{ General practice contacts } & \multicolumn{3}{|c|}{ Accident and emergency attendances } & \multicolumn{3}{|c|}{ Total events } \\
\hline & $\begin{array}{l}R^{2} \\
(\%)\end{array}$ & $\begin{array}{l}\text { B coefficient (95\% } \\
\text { confidence interval) }\end{array}$ & $\begin{array}{c}P \\
\text { value }\end{array}$ & $\begin{array}{l}R^{2} \\
(\%)\end{array}$ & $\begin{array}{l}\text { B coefficient ( } 95 \% \\
\text { confidence interval) }\end{array}$ & $\begin{array}{c}P \\
\text { value }\end{array}$ & $\begin{array}{l}R^{2} \\
(\%)\end{array}$ & $\begin{array}{l}\text { B coefficient (95\% } \\
\text { confidence interval) }\end{array}$ & $\begin{array}{c}P \\
\text { value }\end{array}$ \\
\hline Jarman score & 46 & $1.5(0.8$ to 2.2$)$ & 0.0004 & 43 & $0.9(0.4$ to 1.3$)$ & 0.001 & 58 & $2.4(1.5$ to 3.3$)$ & $<0.0001$ \\
\hline Townsend score & 42 & 6.7 (3.1 to 10.2$)$ & 0.0008 & 44 & 4.1 (2.0 to 6.2$)$ & 0.0006 & 56 & $10.8(6.5$ to 15.1$)$ & $<0.0001$ \\
\hline $\begin{array}{l}\text { Distance from accident and } \\
\text { emergency department }\end{array}$ & 14 & $-6.4(-13.6$ to 0.8$)$ & 0.08 & 34 & $-6.1(-10$ to -2.2$)$ & 0.003 & 26 & $-12.5(-21.9$ to -3.0$)$ & 0.01 \\
\hline Single parent† & 66 & $13.0(8.8$ to 17.2$)$ & $<0.0001$ & 23 & $4.7(0.8$ to 8.5$)$ & 0.02 & 62 & 17.7 (11.4 to 24.0$)$ & $<0.0001$ \\
\hline Overcrowding†‡ & 42 & $11.0(5.1$ to 16.9$)$ & 0.0008 & 45 & 7.0 (3.5 to 10.4$)$ & 0.0004 & 56 & 18.0 (10.8 to 25.2$)$ & $<0.0001$ \\
\hline No carł & 37 & $1.7(0.7$ to 2.7$)$ & 0.002 & 45 & $1.2(0.5$ to 1.7$)$ & 0.0004 & 52 & $2.9(1.6$ to 4.1$)$ & 0.0001 \\
\hline Housing tenureł & 39 & $1.4(0.6$ to 2.2$)$ & 0.001 & 36 & $0.8(0.3$ to 1.3$)$ & 0.002 & 50 & 2.2 (1.2 to 3.2$)$ & 0.0002 \\
\hline Unemployment†‡ & 37 & 3.7 (1.5 to 5.8$)$ & 0.02 & 34 & $2.1(0.8$ to 3.5$)$ & 0.003 & 47 & 5.8 (3.0 to 8.6$)$ & 0.0003 \\
\hline Ethnicity† & 26 & $3.0(0.7$ to 5.3$)$ & 0.01 & 38 & 2.2 (0.9 to 3.5$)$ & 0.02 & 39 & $5.2(2.2$ to 8.1$)$ & 0.001 \\
\hline Moved within year† & 9 & 2.5 (-1.1 to 6.0$)$ & 0.1 & 30 & 2.7 (0.8 to 4.6$)$ & 0.007 & 20 & $5.2(0.5$ to 9.9$)$ & 0.03 \\
\hline Children aged $<5 \dagger$ & 22 & 17.0 (2.6 to 31.6$)$ & 0.02 & 4 & $4.7(-5.1$ to 14.5$)$ & 0.33 & 18 & 21.7 (0.7 to 42.7$)$ & 0.04 \\
\hline Unskilled† & 9 & $9.0(-4.2$ to 22.3$)$ & 0.17 & 1 & $1.7(-6.8$ to 10.0$)$ & 0.68 & 6 & 10.7 (-8.3 to 29.7) & 0.25 \\
\hline Elderly living alone† & 2 & $3.1(-5.7$ to 11.9$)$ & 0.47 & 5 & $2.6(-2.6$ to 8.0$)$ & 0.3 & 4 & 5.8 (-6.6 to 18.0$)$ & 0.34 \\
\hline
\end{tabular}

* Single parent=households of 1 person aged $>16$ years and $\geqslant 1$ children aged $<16$, as percentage of residents in private households; overcrowding=people in households living at $>1$ person/room, as percentage of residents in private households; no car=percentage of households without access to a car; housing tenure=percentage of homes not owner occupied; unemployment=people aged $\geqslant 16$ seeking work, as percentage of residents in private households; ethnicity=people in households headed by a person born in the New Commonwealth, as percentage of residents in private households; moved within year=people aged $\geqslant 1$ year with a usual address one year before the census different from the present usual address, as percentage of total residents; children aged $<5=$ children $<5$, as percentage of residents in private households; unskilled=people in households headed by a person in socioeconomic group 11, as percentage of residents in private households; elderly living alone=pensioners living alone, as percentage of residents in private households.

†Variable included in Jarman score.

fVariable included in Townsend score.

Some variables common to both Jarman and Townsend scores are calculated slightly differently, in which case univariate analyses are based on the Jarman definition. 
score of 60 between two wards would predict a difference of 144 out of hour events/1000 patients/year (95\% confidence interval 90 to 198), which is more than half the overall average.

The Jarman score, which is used to determine general practice deprivation payments, performed slightly better than the alternative Townsend score in explaining out of hours activity. The analysis of individual census components must be interpreted with caution. Because a variable is associated with out of hours activity on an area basis does not necessarily mean that individuals with that characteristic consult more (the ecological fallacy). ${ }^{18}{ }^{19}$ It has also been shown for general practice consultation rates that some socioeconomic factors such as single parents and ethnicity have different effects in different parts of the country. ${ }^{20}$ Nevertheless, it is interesting that the variables of children under 5 and single parents were more important for general practice contacts while a change of address within the previous year was associated with accident and emergency rates. It should be borne in mind that the accident and emergency rates for each ward were practice specific and so took no account of deprived patients who were not registered with a general practitioner. ${ }^{21}$

Multivariate analysis showed that one practice (which was the most deprived) had significantly higher out of hours rates even when deprivation was included in the regression equation. This was apparent from the raw data, which showed markedly different rates for different practices for the same wards. Similar substantial practice effects on out of hours rates have been described before ${ }^{22}$; they could be mediated either by practice factors influencing patient demand or by differences within the patient populations not detected by census variables at ward level.

\section{Conclusions}

Out of hours activity is currently undergoing dramatic change. ${ }^{23}$ Out of hours payments now have a flat rate component with less emphasis on item of service payment. There is increased use of cooperatives, which usually involves a payment proportional to the number of calls delegated. There have recently been proposals to try to redirect some accident and emergency attendances to primary care. ${ }^{24}$ Those involved in changing out of hours services should take into account the wide variations in demand we have described. A disproportionate amount of activity falls on deprived inner city practices; these practices already have the most difficulty recruiting new partners. The challenge is to find ways of supporting such practices to provide good quality out of hours care.

We thank the participating general practitioners.

Contributors: AJA and SE conceived of the idea for the study and prepared the grant application. The project team, led by AJA, consisted of LMG, DB, SE, and RC. Clive Richards attended early project meetings and gave helpful advice. DB collected the data and, with Edna Gibson, entered the data, with advice from LMG and AJA. LMG and AJA performed data analysis for the overall study, and RC performed specific analysis for this paper with statistical advice from Carol Coupland. $\mathrm{RC}$ wrote the paper with input from all members of the project team. Brian Thompson-Bialy provided data on the deputising service; Andrew Dove and James Scott provided data on the accident and emergency service; Chris Kerry, Jean Robinson, Christine Edwards, and Saalije Howard provided data on practice populations; Dave Ebdon calculated distance and census
Key messages

- We studied the out of hours activity of six general practices and the local accident and emergency department in Nottingham for six months

- There were wide variations between electoral wards in both general practice and accident and emergency events

- Deprivation scores explained more than half of the variation, with out of hours activity being highest in deprived inner city areas

- Highly deprived areas close to the accident and emergency department generated high levels of work for both general practice and accident and emergency services, with no evidence of one service substituting for the other

information; and Professor Jarman and Debbie Hart provided deprivation scores and census information.

Funding: Grant from Nottingham Health Authority.

Conflict of interest: None.

1 Hallam L. Primary medical care outside normal working hours: review of published work. BMJ 1994;308:249-53.

2 Livingstone AE, Jewell JA, Robson J. Twenty four hour care in inner cities: two years' out of hours workload in east London general practice. BMJ 1989;299:368-70.

3 Carlisle RD, Johnstone SP, Pearson JC. Relation between night visit rates and deprivation measures in one general practice. BMJ 1993;306:1383-5.

Pitts J, Whitby M. Out of hours workload of a suburban general practice: deprivation or expectation? $B M J 1990 ; 300: 1113-5$

5 Majeed FA, Cook DG, Hilton S, Poloniecki J, Hagen A. Annual night visiting rates in 129 general practices in one family health service authority: association with patient and general practitioner characteristics. BrJ Gen Pract 1995;45:531-5.

6 Whynes DK, Baines DL. Explaining variations in the frequency of night visits in general practice. Fam Pract 1996;13:174-8.

7 Milner PC, Nicholl JP, Williams BT. Variation in demand for accident and emergency departments in England from 1974 to 1985. J Epidemiol Community Health 1988;42:274-8.

8 Williams B, Nicholl J, Brazier J. Accident and emergency departments. In: Stevens A, Rafferty J, eds. Health care needs assessment II. Oxford: Radcliffe Medical Press, 1996:24-6.

9 Jankowski RF, Mandalia S. Comparison of attendance and emergency admission patterns at accident and emergency departments in and out of London. BMJ 1993;306:1241-3.

10 Tomlinson B. Report of the inquiry into London's health service, medical education and research. London: HMSO, 1992.

11 Iliffe S, Haug U. Out of hours work in general practice. BMJ 1991;302:1584-6.

12 Jarman B. Identification of underprivileged areas. BMJ 1983;286:1705-9.

13 Townsend P, Phillimore P, Beattie A. Health and deprivation. London: Croom Helm, 1988.

14 Moore AT, Roland MO. How much variation in referral rates among general practitioners is due to chance? BMJ 1989;298:500-2.

15 McKee CM, Gleadhill DN, Watson JD. Accident and emergency attendance rates: variation among patients from different general practices. Br J Gen Pract 1990;40:150-3.

16 Ben-Shlomo Y, White I, McKeigue PM. Prediction of general practice workload from census based social deprivation scores. J Epidemiol Community Health 1992;46:532-6.

17 Wilkin D. Patterns of referral: explaining variation. In: Roland M, Coulter A, eds. Hospital referrals. Oxford: Oxford University Press, 1992:76-91.

18 MacRae K. Socio-economic deprivation and health and the ecological fallacy. BMJ 1994;309:1478-9.

19 Majeed FA, Cook DG, Poloniecki J, Griffiths J, Stones C. Sociodemographic variables for general practices: use of census data. $B M J$ 1995;310:1373-4.

20 Carr-Hill RA, Rice N, Roland M. Socio-economic determinants of rates of consultation in general practice based on fourth national morbidity survey of general practices. BMJ 1996;312:1008-12.

21 Dale J, Green J, Reid F, Glucksman E. Primary care in the accident and emergency department: I. Prospective identification of patients. BMJ 1995;311:423-6.

22 Usherwood T, Kapski M, Barber J. Wide variations in the night visiting rate. J $R$ Coll Gen Pract 1985;35:395.

23 Hallam L. Out of hours primary care. BMJ 1997;314:157-8.

24 Calman K. Developing emergency services in the community. London: Department of Health, 1996.

(Accepted 22 October 1997) 


\title{
The use of out of hours health services: a cross sectional
}

\section{survey}

\author{
Catherine Brogan, Diane Pickard, Alastair Gray, Steve Fairman, Alison Hill
}

See $p 520$

Anglia and Oxford

Regional Office

NHS Executive,

Linford Wood,

Milton Keynes

MK14 6QP

Catherine Brogan,

Consultant in public

health medicine

Buckinghamshire

Health Authority,

Verney House,

Aylesbury

HP19 3ET

Diane Pickard,

research and

development specialist

nurse

Steve Fairman,

information manager

Alison Hill,

director of public

health

Health Economics

Research Centre,

University of

Oxford, Institute of

Health Sciences,

Oxford OX3 7LF

Alastair Gray,

director

Correspondence to: Dr Brogan

BMJ 1998;316:524-7

\section{Abstract}

Objectives: To determine the use and costs of the principal out of hours health services in Buckinghamshire.

Design: Prospective cross sectional survey and cost description of patient contacts with out of hours services.

Setting: Buckinghamshire during March and April 1995.

Subjects: General practices, accident and emergency departments, ambulance services, and community nursing services.

Main outcome measure: Contacts with patients and cost of out of hours services.

Results: 438 patient contacts/1000 population/year were recorded at an annual incremental cost of between $£ 4.6 \mathrm{~m}$ and $£ 7.2 \mathrm{~m}$ (depending on the costing of general practitioner services), for a population of 660000 . Of these contacts, 21649 (45\%) were with general practitioners. Night time contacts with all services diminished sharply after $10 \mathrm{pm}$. General practitioners considered that $40 \%$ of contacts were unnecessary or could have waited until morning. Over $70 \%$ of contacts were for upper respiratory tract infections, earache, gastroenteritis, and other minor ailments. Nursing care was predominantly for elderly people, and $33 \%$ of nursing contacts were to supervise medication. Accident and emergency care was predominately for young adults, especially men, and $41 \%$ of attendances were for medical conditions. Conclusions: New models such as multidisciplinary primary care centres with telephone advice lines and triaging are required to ensure high quality, cost effective care that is responsive to the needs of both consumers and professionals.

\section{Introduction}

British general practitioners' contracts give them 24 hour responsibility for their patients. The component of total remuneration related to out of hours work has never been made explicit, but such work has increasingly been seen as an important source of stress and low morale among general practitioners, ${ }^{12}$ leading to demands that pay for out of hours work should be explicitly stated and negotiated. This dispute has stimulated interest in the volume, patterns, use, and costs of out of hours health services. Previous studies have documented the increasing demand for general practitioners' services, ${ }^{3}$ audited the demand for deputising services ${ }^{4}$ and rates of payments for night visits, ${ }^{5}$ and drawn attention to the costs of out of hours hospital services such as surgical procedures. ${ }^{67}$

Our study was undertaken to inform debate and future policy in this area by recording the volume and characteristics of all out of hours demands for a broad range of health services and to assess the incremental costs associated with providing such out of hours care.

\section{Methods}

We contacted all general practices, cooperatives, deputising services, accident and emergency departments, ambulance services, and evening nursing services in Buckinghamshire and invited them to participate in the study: $84 \%$ of general practices and $100 \%$ of other service providers agreed to participate. The participating general practices were representative in terms of location, size, and other known characteristics, and we adjusted the contacts with general practitioners recorded in the survey by a factor of 1.19 to compensate for the incomplete participation of general practitioners in the county.

We used routine data collection sources and specially prepared data collection sheets to obtain information from each service provider on all out of hours contacts from 1 March to 30 April 1995. The out of hours periods were defined as $7 \mathrm{pm}$ to $8 \mathrm{am}$ on weekdays, weekends ( 8 am Saturday to 8 am Monday), and bank holidays ( 8 am to 8 am the next day). We estimated annual rates by calculating the average number of contacts over the study during each weekday night, and during each 24 hour period of weekends and bank holidays, and multiplying by 251 weekday nights and by 114 weekend or bank holiday 24 hour periods.

We estimated incremental costs of out of hours services by identifying the additional or incremental resources required by each group of service providers to provide their services. We attached unit costs to these resources. Thus the items of cost included varied with different service providers, making direct comparison difficult. We calculated unit costs of staff time by using mid-points of salary scales prevailing in April 1995, including all employers' costs. We costed non-staff resources such as transport and accommodation as opportunity costs, using accounting and cost information within each service area. Prices were expressed in 1995 terms.

\section{Results}

\section{All services}

A total of 47828 patient contacts were recorded from 1 March to 30 April 1995 during the defined out of hours periods (table 1): $21649(45 \%)$ were with general practitioners, 12908 (27\%) with accident and emergency departments, 11318 (24\%) with home nursing services, and 1953 (4\%) with ambulance services.

Table 2 shows the broad pattern of contacts by out of hours period. For most service providers, over half of weekday evening contacts occurred between $7 \mathrm{pm}$ and $10 \mathrm{pm}-$ that is, before payments for night visits begin (fees can be claimed for visits between $10 \mathrm{pm}$ and $8 \mathrm{am})$. However, contacts with ambulance services were more evenly spread throughout the evening and night. 
Table 3 shows contact rates by patients' age and service provider. Overall, the recorded contact rate was equivalent to 438 contacts/1000 population/year. The contact rates with general practitioners and accident and emergency departments were broadly $U$ shaped with respect to patients' age, while the contact rate with home nursing services rose steadily with age.

\section{General practice}

Of the 92 general practices in the county, 77 (84\%) recorded 18193 out of hours contacts with patients: after adjustment for non-participation, this was equivalent to 21649 contacts for the county as a whole. Of the recorded contacts, $7577(35 \%)$ were home visits, $8010(37 \%)$ were surgery visits, and $6062(28 \%)$ were telephone advice. A total of 2963 fees for night visits were paid across the county. On weekdays the number of contacts was highest during 7 pm-10 pm (on average, $51 \%$ of contacts occurred during this period). The number of contacts then fell sharply until midnight and remained low until about 6 am.

In the survey we asked general practitioners to classify all contacts, using a four point scale, according to their perceived urgency. Overall, $1082(5 \%)$ contacts were classified as urgent, $11907(55 \%)$ were considered necessary, $5629(26 \%)$ could have waited until the next morning, and 3031 (14\%) were unnecessary.

Diagnostic information was available for 13555 $(75 \%)$ of these contacts, and there was no evidence that these were unrepresentative of all contacts. The main diagnostic areas were upper respiratory tract infection (3130, 23\%), diarrhoea and vomiting (1646, 12\%), ear infections (1051, 8\%), chest infections (959, 7\%), abdominal pains $(641,5 \%)$, skin complaints $(611,5 \%)$, injuries (592, 4\%), medications (592, 4\%), and urinary tract infections $(506,4 \%)$.

\section{Accident and emergency services}

During the study, 12908 patients attended the three accident and emergency departments in Buckinghamshire for out of hours care. Detailed information on the source and reason for referral, and mode of transport, was available from the departments for 4651 (37\%) of contacts. Of the records that were valid, $79 \%$ (3620/4576) were self referred, and the main reasons for attending were injuries $(29 \%, 1325 / 4651)$, lacerations $(11 \%, 501 / 4651)$, fractures $(5 \%, 225 / 4651)$, and foreign bodies $(3 \%, 137 / 4651)$. However, the third largest category of referral types $(9 \%, 422 / 4576)$ were patients referred by a general practitioner to another specialty, such as medicine or neurology. For these patients, the accident and emergency department was primarily a gatekeeper to the hospital.

A negligible proportion of all patients came via public transport, with $77 \%(3585 / 4651)$ arriving by private transport, $21 \%$ (959) by ambulance, and $2 \%$ (81) walking. As with general practitioner contacts, just over half $(55 \%)$ of weekday evening contacts were between $7 \mathrm{pm}$ and $10 \mathrm{pm}$.

\section{Ambulance}

Eight ambulance sites across Buckinghamshire provide out of hours services. During the study, these recorded 1953 out of hours contacts: $1523(78 \%)$ were emergency ("999") calls, and 430 (22\%) were "urgent" calls requested by a doctor. A total of $1523(78 \%)$
Table 1 Number (percentage) of patients' out of hours contacts with health service providers in Buckinghamshire during March and April 1995 by patients' age

\begin{tabular}{lccccc}
$\begin{array}{l}\text { Patients' age } \\
\text { (years) }\end{array}$ & $\begin{array}{c}\text { General } \\
\text { practitioners }\end{array}$ & $\begin{array}{c}\text { Accident and } \\
\text { emergency }\end{array}$ & Home nursing & Ambulance & All services \\
\hline $0-9$ & $6775(31)$ & $2268(17)$ & $29(<1)$ & - & $9072(19)$ \\
\hline $10-19$ & $1719(8)$ & $2386(19)$ & $50(<1)$ & - & $4155(9)$ \\
\hline $20-29$ & $2377(11)$ & $2556(20)$ & $118(1)$ & - & $5051(10)$ \\
\hline $30-39$ & $2502(12)$ & $1665(13)$ & $313(3)$ & - & $4480(9)$ \\
\hline $40-49$ & $1795(8)$ & $1243(10)$ & $789(7)$ & - & $3828(8)$ \\
\hline $50-59$ & $1352(6)$ & $759(6)$ & $768(7)$ & - & $2878(6)$ \\
\hline $60-69$ & $1138(5)$ & $549(4)$ & $1481(13)$ & - & $3168(7)$ \\
\hline $70-79$ & $1190(5)$ & $533(4)$ & $2627(23)$ & - & $4349(9)$ \\
\hline$\geqslant 80$ & $1514(7)$ & $525(4)$ & $4876(43)$ & - & $6915(14)$ \\
\hline Unknown & $1287(6)$ & $424(3)$ & $268(2)$ & 1953 & $3931(8)$ \\
\hline Total & 21649 & 12908 & 11318 & 1953 & 47828 \\
\hline
\end{tabular}

Table 2 Number (percentage) of patients' out of hours contacts with health service providers during March and April 1995 by time period and service category

\begin{tabular}{|c|c|c|c|c|c|}
\hline \multirow[b]{2}{*}{ Health service provider } & \multicolumn{3}{|c|}{ Weekday evenings } & \multirow{2}{*}{$\begin{array}{l}\text { Weekend or } \\
\text { bank holiday } \\
\text { (8 am-8 am) }\end{array}$} & \multirow{2}{*}{$\begin{array}{c}\text { All out of } \\
\text { hours contacts }\end{array}$} \\
\hline & 7 pm-10 pm & 10 pm-8 am & All & & \\
\hline General practitioners & $2834(13)$ & $2677(12)$ & $5511(25)$ & $16138(75)$ & $21649(45)$ \\
\hline Accident and emergency & $2665(21)$ & $2172(17)$ & 4837 (38) & $8071(62)$ & $12908(27)$ \\
\hline Ambulance & $496(25)$ & $620(32)$ & $1116(57)$ & $837(43)$ & $1953(4)$ \\
\hline Home nursing & $1802(16)$ & $1273(11)$ & $3075(27)$ & $7215(63)$ & $11318(24)$ \\
\hline Total & 7797 & 6742 & 14539 & 32261 & 47828 \\
\hline
\end{tabular}

Table 3 Out of hours contact rate (No of contacts/1000 population/year) by service provider and patients' age

\begin{tabular}{lccccc}
$\begin{array}{l}\text { Patients' } \\
\text { age (years) }\end{array}$ & $\begin{array}{c}\text { General } \\
\text { practitioners }\end{array}$ & $\begin{array}{c}\text { Accident } \\
\text { and } \\
\text { emergency }\end{array}$ & $\begin{array}{c}\text { Home } \\
\text { nursing }\end{array}$ & $\begin{array}{c}\text { All } \\
\text { Ambulance }\end{array}$ & \begin{tabular}{c} 
services \\
\hline $0-9$
\end{tabular} \\
\hline 73 & 154 & 2 & - & 629 \\
\hline $10-19$ & 128 & 172 & 4 & - & 304 \\
\hline $20-29$ & 158 & 165 & 8 & - & 330 \\
\hline $30-39$ & 155 & 100 & 19 & - & 273 \\
\hline $40-49$ & 114 & 77 & 48 & - & 239 \\
\hline $50-59$ & 120 & 65 & 66 & - & 251 \\
\hline $60-69$ & 137 & 64 & 172 & - & 373 \\
\hline $70-79$ & 207 & 90 & 440 & - & 737 \\
\hline$\geqslant 80$ & 464 & 157 & 1441 & - & 2062 \\
\hline All ages & 197 & 117 & 103 & 21 & 438 \\
\hline
\end{tabular}

patients were transported to hospital, while the rest did not require hospitalisation.

The distribution of ambulance contacts over time was less skewed towards the $7 \mathrm{pm}-10 \mathrm{pm}$ period than was the case with general practitioner and accident and emergency contacts: $859(44 \%)$ of the contacts occurred between $7 \mathrm{pm}$ and $10 \mathrm{pm}$, while 1094 (56\%) occurred during 10 pm-8 am.

\section{Nursing services}

Three hospital trusts provided out of hours nursing services, from early evening to midnight. The nurses had no formal response role and essentially provided home visits that had been prearranged. Of the total of 11318 contacts recorded during the study, only 792 (7\%) were with new patients while 10526 (93\%) were follow up calls.

Each trust maintained a slightly different classification system for recording information about diagnosis and category of care. However, 3056 (27\%) of all visits were for ongoing nursing assessment, advice, and support; 2490 (22\%) were related to the control and administration of drugs; 2037 (18\%) were 
Table 4 Costs (£) of patients' out of hours contacts with health service providers during March and April 1995 by time period and service category, and estimated yearly cost per 1000 population

\begin{tabular}{|c|c|c|c|c|c|c|}
\hline \multirow[b]{2}{*}{ Health service provider } & \multicolumn{3}{|c|}{ Weekday evenings } & \multirow{2}{*}{$\begin{array}{c}\text { Weekend } \\
\text { or bank } \\
\text { holiday } \\
\text { (8 am-8 am) }\end{array}$} & \multirow{2}{*}{$\begin{array}{l}\text { All out of } \\
\text { hours } \\
\text { contacts }\end{array}$} & \multirow{2}{*}{$\begin{array}{c}\text { Yearly cost } \\
\text { per } 1000 \\
\text { population }\end{array}$} \\
\hline & $\begin{array}{l}7 \mathrm{pm}- \\
10 \mathrm{pm}\end{array}$ & $\begin{array}{l}10 \mathrm{pm}- \\
8 \mathrm{am}\end{array}$ & All & & & \\
\hline \multicolumn{7}{|l|}{ General practitioners: } \\
\hline Based on night visit fees & - & - & - & - & 144720 & 1317 \\
\hline Based on cooperative model & 85608 & 97170 & 182778 & 404260 & 587038 & 5190 \\
\hline Accident and emergency & 39104 & 88416 & 127520 & 127818 & 255338 & 2288 \\
\hline Ambulance & 29110 & 93193 & 122303 & 109720 & 232023 & 2083 \\
\hline Home nursing & 28292 & 20502 & 48794 & 98660 & 147454 & 1306 \\
\hline Total (based on night visit fees) & - & - & - & - & 779535 & 6994 \\
\hline $\begin{array}{l}\text { Total (based on cooperative } \\
\text { model) }\end{array}$ & $\begin{array}{r}182114 \\
(15 \%)\end{array}$ & $\begin{array}{r}299280 \\
(24 \%)\end{array}$ & $\begin{array}{r}481395 \\
(39 \%)\end{array}$ & $\begin{array}{r}740458 \\
(61 \%)\end{array}$ & 1221853 & 10867 \\
\hline
\end{tabular}

Table 5 Costs $(£)$ per patient out of hours contact with health service providers during March and April 1995 by time period and service category

\begin{tabular}{|c|c|c|c|c|c|}
\hline \multirow[b]{2}{*}{ Health service provider } & \multicolumn{3}{|c|}{ Weekday evenings } & \multirow{2}{*}{$\begin{array}{l}\text { Weekend or } \\
\text { bank holiday } \\
\text { (8 am-8 am) }\end{array}$} & \multirow{2}{*}{$\begin{array}{c}\text { All out of } \\
\text { hours } \\
\text { contacts }\end{array}$} \\
\hline & $7 \mathrm{pm}-10 \mathrm{pm}$ & $10 \mathrm{pm}-8 \mathrm{am}$ & All & & \\
\hline \multicolumn{6}{|l|}{ General practitioners: } \\
\hline Based on night visit fees & - & - & - & - & 6.68 \\
\hline Based on cooperative model & 30.21 & 36.30 & 33.17 & 25.05 & 27.12 \\
\hline Accident and emergency & 14.67 & 40.71 & 26.36 & 15.84 & 19.78 \\
\hline Ambulance & 58.69 & 150.31 & 109.59 & 131.09 & 118.80 \\
\hline Home nursing & 15.70 & 16.10 & 15.87 & 13.67 & 13.03 \\
\hline Total (based on night visit fees) & - & - & - & - & 16.30 \\
\hline Total (based on cooperative model) & 23.36 & 44.39 & 33.11 & 22.95 & 25.55 \\
\hline
\end{tabular}

for the care of dressings and leg ulcers; 1019 (9\%) were for administering eye drops; $792(7 \%)$ were related to palliative care; and 453 (4\%) were concerned with continence, bladder, and bowel care.

\section{Costs}

Table 4 summarises the estimated costs of providing out of hours services during the study and the estimated yearly cost per 1000 patients.

General practice-This was the most difficult service to cost because only a fraction of it is covered directly by fees. The payments for night visits made during the study totalled $£ 145000$, equivalent to $£ 1317 / 1000$ population/year. However, we also made an alternative estimate of cost by calculating the actual fixed and variable running costs of a cooperative providing services in part of the county and then estimating the costs of extending this service across the county. Fixed costs were those for premises, radio, overhead staff, and computing, while fully variable costs were those for cars, drivers, fuel, stationery, and general practitioner session fees. If this service model had been used to provide all general practice services the total cost during the study would have been $£ 587000$, equivalent to $£ 5190 / 1000$ population/year.

Accident and emergency services-Costs were defined in terms of staff employed during the relevant periods. The total cost of medical, nursing, and receptionist staff during the study was $£ 255000$, equivalent to $£ 2290 / 1000$ population/year.

Ambulance service-The total cost, based on staffing costs and variable operating costs during out of hours periods, was $£ 232000$ during the study, equivalent to $£ 2080 / 1000$ population/year.

Nursing services -We identified the costs as those of the staff plus transport and other expenses directly associated with out of hours calls. These totalled $£ 147000$ over the study, equivalent to $£ 1306 / 1000$ population/year.

In total, therefore, the cost of all out of hours health services was equivalent to between $£ 6990$ and $£ 10870 / 1000$ population/year, or a total annual cost of between $£ 4.6 \mathrm{~m}$ and $£ 7.2 \mathrm{~m}$ across Buckinghamshire. Although most contacts during weekday evenings occurred during 7 pm-10 pm, only $15 \%$ of out of hours resources were devoted to this period compared with $24 \%$ allocated to the period $10 \mathrm{pm}-8 \mathrm{am}$.

Table 5 shows the cost per contact by out of hours period and service provider. The highest cost per contact was for the ambulance service, at $£ 119$ per patient contact. For general practitioners, the cost based on the general practitioner cooperative model was $£ 27.12$ per contact, whereas the cost based on payments for night visits was $£ 6.68$ per contact. Accident and emergency and home nursing services had costs per contact of $£ 20$ and $£ 13$ respectively.

\section{Discussion}

Out of hours health services have developed with little planning or coordination, and the resulting pattern of provision is unsatisfactory to providers such as general practitioners and may not be the most appropriate use of resources. The results of this comprehensive survey of out of hours services give a reasonably accurate quantitative estimate of the numbers, types, and costs of contacts with different services in Buckinghamshire. It provides a basis for considering options for change.

We did not measure cross boundary flows and assumed that the flows in and out were roughly equal. The pattern of local services, cross boundary flows, and seasonal variations should be considered before generalising these findings elsewhere.

\section{Costs of general practitioner services}

About a half of all out of hours contacts were with general practitioners, but this service was particularly difficult to cost. Payments for night visits totalled $£ 145000$ during the study, but only $39 \%$ of the home visits were made during the defined out of hours periods, and only $14 \%$ of all recorded contacts were reimbursed via the system of night visit fees. Hence, many of the costs of out of hours services provided by general practitioners are currently not reflected in night visit fees.

If all the general practitioner services had been provided by means of the model of a local cooperative the cost would have been about $£ 587000$, roughly four times the level of night visit fees. To the extent that cooperative costs are funded by general practitioners from their capitation budgets, this may not be a net cost to the NHS. In practice, extending the cooperative model might be possible only by paying higher general practitioner session fees than those agreed between the general practitioners in the cooperative, in turn increasing the costs of this mode of service delivery.

Our results therefore highlight the need for more detailed assessment of the range of general practitioner cooperatives now in existence. To date, only one evaluation of a general practice out of hours cooperative has been published, and this did not give any information about costs. ${ }^{8}$ The running costs of the cooperative in our study were at the upper end of the 
range of development funding requirements reported in a recent brief survey of 36 cooperatives, ${ }^{9}$ but the comparability of these figures with our study is uncertain. We emphasise that the cost data presented here may not be representative of other cooperative models elsewhere in Britain.

\section{Appropriateness of patient contacts}

The general practitioners considered many patient contacts to be fairly trivial. They felt that better information could improve the appropriateness of out of hours contacts: possible channels for communication included media campaigns, handbooks, telephone help lines for all out of hours calls answered by trained staff using protocols to triage patients, recorded advice, and health pages on the internet. Insufficient resources were available to include pharmacists in our survey, but their role in providing advice could also be expanded. Patients could be taught specific skills such as instilling their own eye drops with dropper aids.

\section{Integration of services}

Our study raises the issue of skill mix. For example, cooperatives or primary care centres could be multidisciplinary and could triage telephone calls, give advice, and deal with minor injuries. Ambulance workers could be integrated more closely with accident and emergency departments when not responding to emergency calls. Indeed, accident and emergency departments could become the site of primary care centres and use a variety of carers, such as nurse practitioners or paramedics, to deliver appropriate care. Practice nurses could deal with a proportion of calls to general practitioners. ${ }^{10}$ Many of these models are already being developed and evaluated. The settlement reached on out of hours care during 1996 may be dependent on finding sustainable, alternative patterns of organisation. ${ }^{11}$

We are grateful to numerous people in Buckinghamshire for their cooperation and assistance in undertaking the survey. Members of the steering group provided valuable advice and comments; in particular, we acknowledge the support of David Olney, accident and emergency consultant, who died suddenly during the study.

Contributors: CB initiated and coordinated formulation of the cross sectional survey, discussed core ideas, designed the protocol and data analysis, and coordinated interpretation of data and writing of the paper. DP coordinated the study; discussed core ideas; participated in protocol design and collection, interpretation, and analysis of data; and participated in writing of the paper. AG designed and conducted the economic evaluation, discussed core ideas, collected and analysed costing
Key messages

- We studied the use and costs of out of hours health services in Buckinghamshire during April and May 1995

- The system of fees for night visits reimbursed only $39 \%$ of the home visits performed by general practitioners out of hours, and less than one in seven of all recorded patient contacts with general practitioners

- The cost of providing the out of hours services was equivalent to between $£ 6990$ and $£ 10870$ per 1000 population per year

- General practitioners were the largest provider of out of hours services, but about half of all contacts were with other providers-nurses, ambulances, and accident and emergency departments

- Policy changes to cope with growing demand for out of hours care will require much more than changing the general practitioner contract

data, and participated in analysis and writing of the paper. SF designed the database, collated data from various sources, organised the data analysis, and participated in interpretation of data and editing of the paper. AH initiated formulation of the cross sectional survey, discussed core ideas, chaired the steering group, and participated in interpretation of data and editing of the paper. David Eveling participated in design of the database, collated data from various sources, and participated in analysis and interpretation of data. Penny Drewett provided administrative support and entered the data. CB, DP, and AG are guarantors for the paper.

Funding: Buckinghamshire Health Authority; Anglia and Oxford NHS Executive Locally Organised Research programme.

Conflict of interest: None.

1 Pitt J.Hours of work and fatigue in doctors. JR Coll Gen Pract 1988;38:2-3.

2 Hallam L. Primary medical care outside normal working hours; review of published work. $B M J$ 1994;308:249-53.

3 Salisbury C. Visiting through the night. BMJ 1993;306:762-4

4 Soler M, Dowers A, Jones RB. Out of hours work in primary care: audit of an urban co-operative deputising service. Health Bull 1991;49(1):40-7.

5 Hallam L, Cragg D. Organisation of primary care services outsider normal working hours. BMJ 1994;309:1621-3.

6 McKee M, Priest P, Ginzler M, Black N. Which general surgical operations must be done at night? Ann R Coll Surg Engl 1991;73(5):295-301, discussion $301-2$.

7 Yeatman M, Cameron-Smith A, Moore JM. Nocturnal orthopaedic operating: can we let sleeping orthopaedic surgeons lie? Ann R Coll Surg Engl 1994;76(2):90-4

8 Salisbury C. Observational study of a general practice out-of-hours cooperative: measures of activity. BMJ 1997;314:182-6.

9 Jessopp L, Beck I, Hollins L, Shipman C, Reynolds M, Dale J. Changing the pattern of out-of-hours: a survey of general practice cooperatives. the pattern of out-of-hours
$B M J 1997 ; 314: 199-200$.

10 South Wiltshire Out of Hours Project (SWOOP) Group. Nurse telephone triage in out-of-hours primary care: a pilot study. BMJ 1997;314:198-9.

11 Hallam L. Commentary: changing the culture of out-of-hours care. BMJ 1996;312:1402.

(Accepted 22 October 1997)

\section{A memorable patient \\ A Lapland lavage}

Twelve years ago I had my northern exposure in the remotest Finnish Lapland. In the summertime I saw the owls screaming, the bears and the wolves dreaming of the reindeers, millions of mosquitos, and the midnight sun. The winter showed me the Northern Lights flaming on the vast screen in the sky and the thermometers with their mercury frozen at the bottom.

Two hundred kilometres north of the Arctic Circle, trapped in the village with its population of 2500 , I worked as a GP in my little health centre with one colleague. It was late afternoon when an elderly man came in to have his paracentesis to remove the ascites caused by a carcinoid tumour. I did my routines, but suddenly noticed his ascites had an odd colour. Grey and ultimately black material ran freely in the suction tube from his abdomen. I knew where I was. Politely I repeated the paracentesis and the suction with the new equipment, this time finding normally coloured ascites.

No peritonitis developed despite my coloncentesis, and a week later he came back relieved and wondering what I had done to cure his constipation.

Pekka Niemelä, general practitioner, Oulu, Finland 